\title{
THE FML (FUCOSE MANNOSE LIGAND) OF LEISHMANIA DONOVANI. A NEW TOOL IN DIAGNOSIS, PROGNOSIS, TRANSFUSIONAL CONTROL AND VACCINATION AGAINST HUMAN KALA-AZAR
}

\author{
Clarisa B. Palatnik de Sousa, Elza M. Gomes, Edilma Paraguai de Souza, \\ Wania R. dos Santos, Sirley R. de Macedo, Linnete V. de Medeiros and \\ Kleber Luz
}

\begin{abstract}
The Fucose-Mannose Ligand (FML) of Leishmania donovani is a complex ghcoproteic fraction. Its potential use as a tool for diagnosis of human visceral leishmaniasis was tested with human sera from Natal, Rio Grande do Norte, Brazil. The FML-ELISA test, showed IOO\% sensitivity and $96 \%$ specificity, identifying patients with overt kala-azar $(p<0.001$, when compared to normal sera), and subjects with subclinical infection. More than 20\% apparently healthy subjects with positive reaction to FML developed overt kala-azar during the following 10 months. In the screening of homan blood donnors, a prevalence of $5 \%$ of sororeactive subjects was detected, attaining $17 \%$ in a single day. The GP36 glycoprotein of FHL is specifically reconized by human kala-azar sera. The immunoprotective effect of FML on experimental $\mathrm{L}$. donovani infection was tested in swiss albino mice. The protection scheemes included three weekly doses of FML, supplemented or not with saponin by the subcutaneous or intraperitoneal routes and challenge with $2 \times 10^{7}$ amastigotes of Leishmania donovani. An enhancement of $80.0 \%$ in antibody response $(p<0.001)$ and reduction of $85.5 \%$ parasite liver burden $(p<0.001)$ was detected in aninals immunized with FML saponin, unrespectively of the immunization route.
\end{abstract}

Key-words: Glycoconjugate. Leishmania donovani. Diagnosis. Prognosis. Kala-azar. Visceral leishmaniasis. Blood transfision. Leishmanial antigens.

Visceral leishmaniasis or kala-azar is a chronic and frequently lethal disease, caused by parasites of the Leishmania donovani complex. The disease is characterized by fever, malaise, loss of weight, hepatomegaly, splenomegaly, anemia, leukopenia, hypergammaglubulinemia and progressive suppression of the cellular immune response. Kalaazar is often fatal if untreated after the onset of symptoms. Furthermore, chemoterapy shows several undesirable colateral effects. The total number of Leishmania infected people all over the world is being estimated in twelve millions. Five hundred thousand of these cases, each year, correspond to visceral leishmaniasis ${ }^{25}$. This number

\footnotetext{
Instituto de Microbiologia. Universidade Federal do Rio de Janeiro. Centro de Hematologia e Hemoterapia-HEMONORTE. Hospital de Doenças Infecciosas Giselda Trigueiro. Departamento de Infectologia. Universidade Federal do Rio Grande do Norte. Address to: Dra. Clarisa B. Palatnik de Sousa. Instituto de Microbiologia/CCS/UFRJ. C. Universitária. I. do Fundão. CP: $68040,21941-590$ Rio de Janeiro, RJ.

Recebido para publicação em 08/01/96.
}

is probably underestimate since an accurate and uniform early diagnose of disease has not yet been established. Visceral leishmaniasis is spreading out in the World due to the increased resistance of parasites to chemoterapy and of insect vectors to insecticides ${ }^{41}$. In Brazil, the disease is disseminating from the North and North-East regions of the country and has recently been described in the State of Rio de Janeiro, previously considered as not endemic ${ }^{20}$.

The current diagnostic in endemic and epidemic areas is still based on clinical analysis and identification of parasites in bone-marrow aspirates. This very invasive method can give positive results in cases of advanced kala-azar. The cure of the disease cannot be monitored, and preclinical patients are not detected, their clinical evolution is not followed-up, and they are a potential reservoir of the disease in endemic areas. Anti-Leishmania circulating antibodies can be detected in human serum soon after infection: they attain high titers with the evolution of the disease and progressively 
disappear after its treatment. The sorologycal diagnosis of kala-azar has been proposed as an alternative by several works, based on antigens that show different degrees of purification, and developping assays with diverse sensitivity and specifficity ranges 5323538 . The stability of these antigens has also been discussed ${ }^{32}$. Nevertheless, a non invassive method of monitorization of the disease was not yet not available in Brazilian Public Health Services.

Infected monocytes, as well as, polymorphonuclear neutrophiles ${ }^{7} 19$ and eosinophiles ${ }^{9}$ were described in the blood, as potential carriers of $L$. donovani parasites from the skin to viscera and bone marrow. In older studies $^{197}$, and in some recent reports on human kala-azar ${ }^{22}$, the presence of infective parasites in the secreta of the upper respiratory and digestive tracts, as well as in urine and faeces were cited. Only occasionally, inoculation of leishmaniasis by the transfusional via were cited ${ }^{10}$. Recent indirect evidences support the need of the study of the blood mediated contamination with kala-azar in humans. Leishmania tropica was identified in bone marrow of american soldiers returning from Operation Desert Storm with viscerotropic leishmaniasis, and for this reason all individuals that traveled to that region were recommended to be deferred as blood donors ${ }^{12}$. Notwithstanding, the existence of a blood-mediated contamination is up to now not admitted as a potential danger for leishmanial infections, and no control of blood is performed for the detection of leishmaniasis in blood banks, even in regions reported to be endemic for kala-azar, and expected to harbor a large number of subjects with subclinical infection.

The analysis of the protective potential of Leishmanial antigens to cutaneous leishmaniasis in murine models has been the focus of detailed studies. The World Health Organization encouraged the development of vaccines for leishmaniasis, using total or partially identified parasite lysates and crude antigens, that could induce a clear prophylactic immune response ${ }^{24}$. This kind of vaccine has shown to be effective against cutaneous leishmaniasis ${ }^{1121}$. The vaccines derived from whole killed Leishmania are in study in Brazil ( $L$. amazonensis), Iran (L. major) and Venezuela ( $L$. mexicana and L. braziliensis) ${ }^{25}$. However, for human visceral leishmaniasis, no vaccine is up to now available. Only few studies on immunization against Leishmania donovani have been undertaken in the murine model, using total parasites ${ }^{26} 1814$ or purified antigens ${ }^{17}$.

In recent studies, we described the isolation of the FML (Fucose Mannose Ligand) of $L$. donovani promastigotes, a complex glycoproteic fraction that strongly inhibits promastigote ${ }^{27}$ and amastigote infection of murine macrophages ${ }^{29}$. Its proteic moiety is mainly composed of acidic and apolar aminoacid residues. Among its neutral sugar components, fucose $(10 \%)$, mannose $(47 \%)$, galactose $(12 \%)$ and glucose $(30 \%)$ were described $^{27}$. FML developped a species-speciffic effect on the inhibition of promastigote uptake by macrophages in vitro ${ }^{28}$. This is a potent antigen for rabbits, hamsters and mice ${ }^{283130}$. Its main antigenic fraction is a $36 \mathrm{kD}$ glycoprotein, recognized by most mouse IgG anti-FML monoclonal antibodies, and present at the surface of both the promastigote and amastigote forms of $L$. donovani parasites ${ }^{29}$. The protective potential of FML on visceral leishmaniasis was analyzed in the isogenic CBhamster model ${ }^{31}$. We studied the effect of three intraperitoneal weekly doses of FML $(100 \mu \mathrm{g})$ in saponin $(100 \mu \mathrm{g})$, followed by an intracardiac injection of $10^{7}$ amastigotes. Protection was speciffic and highly significant $(87.7 \%, p<0.01)$ in the enhancement of anti-FML antibodies titers, of the splenocyte proliferative response, and the intradermal delayed hypersensitivity reaction to antigen, as well as in the decrease of the parasite burden in spleen and of splenomegaly ${ }^{31}$. An analogous study in the inbred balb/c mice model showed an average of $84.2 \%(p<0.001)$ of protection in antibody titers, splenocyte in vitro proliferation and liver parasitic load ${ }^{30}$.

In the present study we report the use of the FML antigen in diagnosis, prognosis ${ }^{32}$ and transfusional control of human visceral leishmaniasis, monitoring the epidemic and endemic disease in Public Health Services of Natal, Rio Grande do Norte, Brazil. This work shows the results obtained with the implementation of the FMLELISA assay in the routine of the laboratory sorologycal screening of the Hospital de Doenças Infecciosas Giselda Trigueiro and the Centro de Hematologia e Hemoterapia-HEMONORTE, with 
Sousa CBP, Gomes EM, Souza EP, Santos WR, Macedo SR, Medeiros LV, Luz K. The FML (Fucose Mannose Ligand) of Leishmania donovani. A new tool in diagnosis, prognosis, transfusional control and vaccination against human kala-azar. Revista da Sociedade Brasileira de Medicina Tropical 29:153-163, 1996.

the support of the Fundação Nacional de Saúde, FNS. Furthermore, preliminary results of the analysis of the FMLvaccine in the outbred swiss albino mouse model, are described.

\section{MATERIAL AND METHODS}

\section{Human sera}

A total of 462 sera was analyzed in this study. A series of 149 sera was collected by the Fundação Nacional de Saúde do Rio Grande do Norte, in the peri-urban area of Natal, RN (North East Brazil), a focus of a recent outbreak of kala-azar. Ten of the sera in this series came from subjects that had a patent kala-azar at the time of serum collection. A series of 26 sera of kala-azar patients, before and during their treatment, was obtained at the Hospital de Doenças Infecciosas Giselda Trigueiro, Natal. All the 36 patients with clinical symptoms of acute kala-azar (loss of weight, lymphadenopathy, hepatomegaly and/or splenomegaly, and fever) were submitted to bone marrow aspiration. Parasitologic analysis confirmed the presence of Leishmania amastigotes in the Giemsa-stained smears. After the serum collection, patients were submitted to antiLeishmania treatment. Thirty five sera of patients that have had kala-azar were collected at least three months after the end of the treatment with antimonials or amphotericin-B, during their clinical and serological follow-up ${ }^{32}$.

Twenty one persons with no patent signs of disease, neighbors and relatives of kala-azar patients, or owners of dogs with L. donovani infection, were also included in the study. We also analyzed the reactivity with FML of 21 sera of patients with cutaneous or mucocutaneous leishmaniasis from Rio de Janeiro and Minas Gerais states, obtained from Dr. S.M. Coutinho, Fundação Oswaldo Cruz, (Rio de Janeiro), 22 sera of fully characterized patients with chronic Chagas disease from Bambuí, Minas Gerais, and 18 sera from healthy adult blood donors from the Hospital Universitário Clementino Fraga Filho, Universidade Federal do Rio de Janeiro, that were screened and considered negative for Chagas disease, HIV I and II, hepatitis, and syphilis $^{32}$. For differential control diagnosis, sera of patients with fever and/or hepatosplenomegaly due to Paracoccidioides brasiliensis infections (1), lymphoma (2), typhus (1) and hemophagocytic disease (1) were obtained from the Departamento de Doenças Infecciosas, UFRJ, and Departamento de Pediatria UERJ, Rio de Janeiro, RJ.

A series of 171 sera of volunteer blood donors was obtained from the blood bank Centro de Hematologia e Hemoterapia-HEMONORTE, and tested for their reactivity with FML. Informed consent for this study was obtained from all the subjects included in this study.

\section{FML-ELISA qualitative assay}

The FML complex was obtained from Leishmania donovani (LD-IS/MHOM/SD/00strain 1S) promastigotes as previously described ${ }^{29}$. Titration of normal human, kala-azar, Chagas' disease and cutaneous leishmaniasis patient's sera pools against FML antigen was performed in order to establish the optimal antigen concentration. The micro-ELISA method was done as described ${ }^{32}$, using FML diluted in carbonate buffer ( $\mathrm{pH} \mathrm{9.6),} \mathrm{to}$ sensitize flat-bottom 96-well plates (Haemobag, Ribeirão Preto, SP, Brazil). Antibodies were detected by peroxidase-labeled protein-A (Sigma, St Louis, MO). Reaction was developed with Ophenyldiamine (Sigma), interrupted with $1 \mathrm{~N}$ sulfuric acid, and monitored at $492 \mathrm{~nm}$. Sera were analyzed by double blind tests, in triplicates, and results expressed as mean values. Positive and negative control sera were included in each test. The absorbance values of sera were compared at 1:100. The cut off limit between the normal sera from a non-endemic area and sera of patients with parasitologically confirmed kala-azar, was identified using the Youden's J inde ${ }^{43}$. Signifficance of the differences between groups of sera was established by a standard $t$ test.

\section{Western Blot analysis}

FML was submitted to SDS-PAGE under reducing conditions, in $10 \%$ slab "baby" gels and transferred to nitrocellulose. Strips were incubated with human sera diluted in blocking buffer, overnight at $4^{\circ} \mathrm{C}$, washed and developed with peroxidaselabeled protein-A followed by diaminobenzidine (Sigma). 
Sousa CBP, Gomes EM, Souza EP, Santos WR, Macedo SR, Medeiros LV, Luz K. The FML (Fucose Mannose Ligand) of Leishmania donovani. A new tool in diagnosis, prognosis, transfusional control and vaccination against human kala-azar. Revista da Sociedade Brasileira de Medicina Tropical 29:153-163, 1996.

\section{Vaccination assays}

2,5 month old swiss albino female mice were obtained from the Biotério Central, Instituto de Microbiologia da UFRJ. Groups of 6-8 females were immunized with three either subcutaneous or intraperitoneal doses of $150 \mu \mathrm{g}$ FML and $100 \mu \mathrm{g}$ saponin (Riedel-de Haën, Seelze, Germany) in $0.2 \mathrm{ml}$ sterile $0.95 \%$ saline, with weekly interval. Saline and saponin treated controls were included. Seven days after immunization, sera were collected and animals were challenged by intravenous injection of $2 \times 10^{7} \mathrm{~L}$. donovani amastigotes, obtained from infected hamster's spleens ${ }^{6}$. Animals were sacrificed by etherization, 15 days after infection, and their liver and spleen parasite-load was monitored in Leishman-Donovan Units of Stauber of Giemsa stained imprintings (LDU = number of amastigotes/ 1000 cell nuclei $x \mathrm{mg}$ organ weight). Sera of animals before and after infection were analyzed by ELISA using $2 \mu \mathrm{g}$ FML/well and reacted with a Peroxidase labeled anti-mouse IgG (Sigma, Co.). ELISA results were expressed as scores (sum of all absorbances at $492 \mathrm{~nm}$, up to the end-point titer) ${ }^{32}$. Statistical comparison of the groups was done by the Student $t$ test.

\section{RESULTS}

Standardization of ELISA experiments was done using FML in dilutions from 0.03 to $2 \mu \mathrm{g}$ per well, reacted with pools of normal human sera from a non-endemic area, sera of patients with kala-azar, tegumentar leishmaniasis and Chagas disease, in dilution 1:2000. The results presented in the Figure 1 , indicated the antigen concentration of $0.125 \mu \mathrm{g} /$ well as the highest that gave no unspecific reaction. All the studied samples were titered and scored in this condition.

The individual absorbance values in FMLELISA assay for 1:100 diluted sera are represented in Figure 2A. The mean value of Abs 1:100 (X \pm $\mathrm{SE}=0.452 \pm 0.038$ ) of patients with acute kalaazar was significantly different from the one of the normal subjects of a nonendemic area $(p<<0.001)$. Eight standard error values separated



Figure I - Determination of FML optimal concentration for ELISA test.

ELISA test of FML reactivity with a normal serum, and sera from patients with tegumentar leishmaniasis, kala-azar or Chagas disease. The arrow indicates the concentration used in ELISA assay standardization. 
Solusa CBP. Gomes EM, Souza EP, Santos WR, Macedo SR, Medeiros LV, Luz K. The FML (Fucose Mannose Ligand) of Leishmania donovani. A new tool in diagnosis, prognosis, transfusional control and vaccination against human kala-azar. Revista da Sociedade Brasileira de Medicina Tropical 29:153-163, 1996.

the two means. The use of mean value $+2 S D$ in the FML-ELISA assay attain the maximal Youden value $=1$, corresponding to the absence of false positive or false negative results (cut off value $=$ $0.204)$. Sera of patients with chronic Chagas disease showed, as expected from standardization experiments, a very reduced reactivity (Abs 1:100 mean value 0.149 ). In the endemic area, (Figure 2B). the FML-ELISA assay functioned as a highly discriminating tool. It allowed to distinguish the non-reactive sera from the endemic area (NE) (n $=86$ ), from the group of subjects without any sign of leishmanial infection but reactive with FML
(RE) $(\mathrm{n}=59)$. We interpret these subjects as a subclinical but active Leishmania infection, in view of their clinical evolution. During the ten months following the first study of 41 sera from the kalaazar outbreak region, nine of the inhabitants of the studied endemic area spontaneously searched medical treatment for the severe disease (NKA). Kala-azar was diagnosed by identification of amastigotes in the bone-marrow aspirate. Among these, six had had high titers of anti-FML antibodies and the highest titers had been observed in two patients that eventually died of severe kala-azar. During the same period, at our knowledge, no
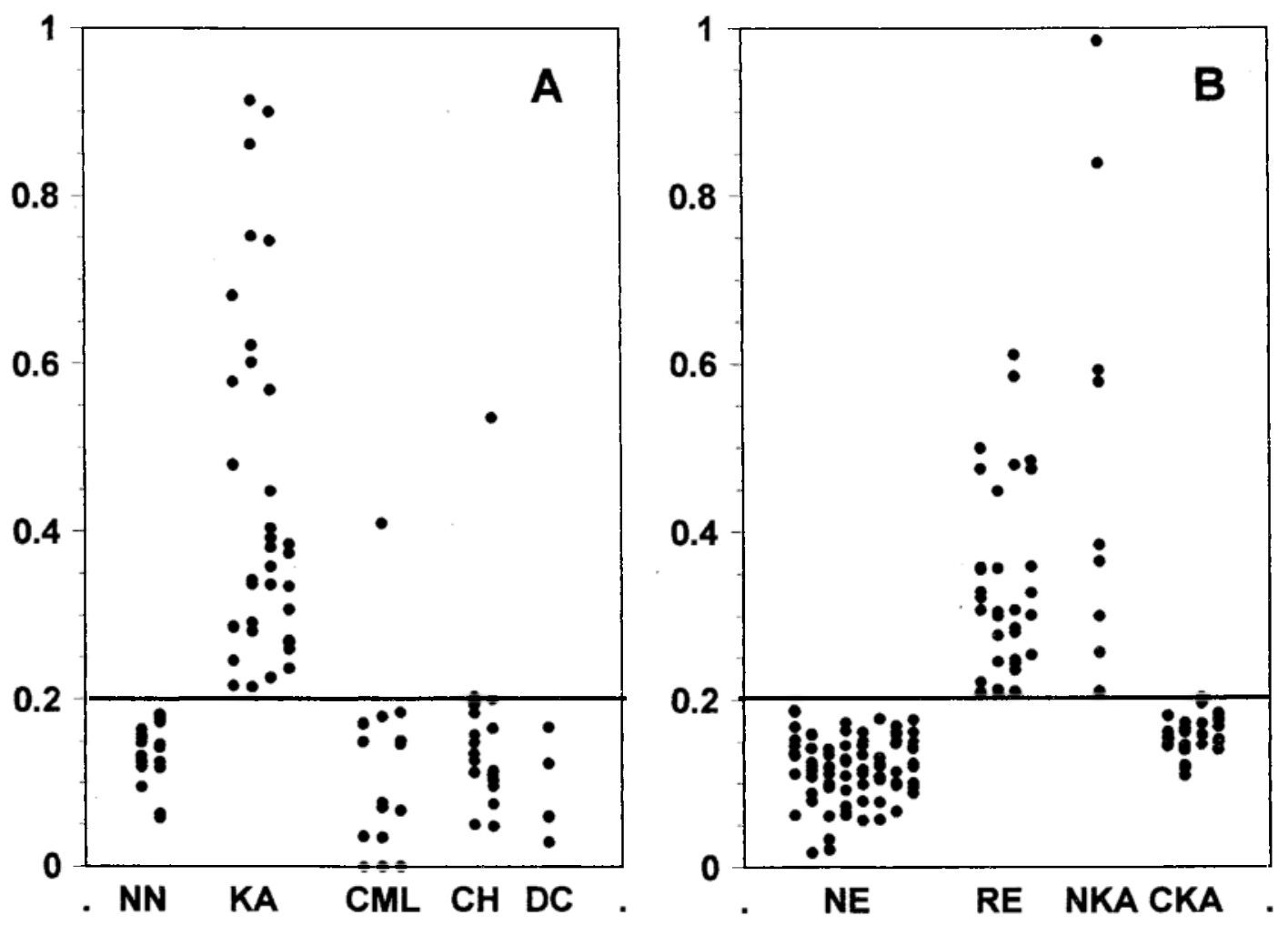

Figure 2 - The FML-ELISA assay in an endemic and non-endemic region for haman visceral leishmaniasis. In A: FML-ELISA reactivity with sera of normal subjects from a non-endemic area (NN), patients with kala-azar diagnosed by the parasitological analysis of bone marrow aspirates $(K A)$, patients with cutaneons or muco-cutaneons leishmaniasis (CML), patients for differential diagnosis (DD) (Paracoccidioides brasiliensis, lymphoma, typhous and hemophagocytic disease), patients with chronic Chagas'disease (CH). In B: normal subjects from an area endemic for kala-azar (NE), subject from the endemic area without overt disease, but reactive with FML (RE), subjects from the endemic area, that had been reactive for FML in the first screening of sera, but did not present at the time overt disease, which developed severe kala-azar in the subsequent ten months period (NKA), and kala-azar patients that have been submitted to anti-parasite treatment and have been cured from the leishmanial infection (CKA). Dots represent absorbance values at sera dilution of 1:100; the horizontal line represents the cut off value (0.204). 
Sousa CBP, Gomes EM, Souza EP, Santos WR, Macedo SR, Medeiros LV, Luz K. The FML (Fucose Mannose Ligand) of Leishmania donovani. A new tool in diagnosis, prognosis, transfusional control and vaccination against human kala-azar. Revista da Sociedade Brasileira de Medicina Tropical 29:153-163, 1996.

subjects with negative reaction to FML developed kala-azar. Consequently, among 41 sera that had shown high or low reactivity with FML but had not clinical signs of kala-azar, more than $20 \%$ developed the overt disease in the ten month period. This number is probably underestimated, since a full clinical and serological survey of the same area has not been completed ${ }^{32}$. Sera of patients with fever and hepatosplenomegaly due to Paracoccidioides brasiliensis infection (1), lymphoma (2) and hemophagocytic disease (1) gave also negative results in the FML-ELISA assay. These results determined $100 \%$ sensitivty and $96 \%$ specificity.

A random monitoring of anti-FML reactivity among 171 volunteer blood donors at the blood bank Centro de Hematologia e HemoterapiaHEMONORTE, Natal, was performed, testing an average of 24.4 diary donor samples, for a period of seven consecutive days. The results obtained are summarized in Table 1. The FML-ELISA test showed the clearly positive reaction for 8 donors. The other 163 samples showed no reactivity $(\mathrm{X}+\mathrm{SE}=0.138+0.002)$. This values represent a total of $5 \%$ of samples and were distributed attaining even $17 \%$ in a single day, no one of which had a positive reaction for Chagas's disease, hepatites, HIV nor syphilis or a decreased hematocrite value. Conversely, among the nonreactive donors, two cases of hepatites B were detected indicating that also in this assay the FML-ELISA showed to be highly specific.

Since the FML components can be separated by electrophoresis, we have analyzed by Western Blot the reactivity of human sera with FML (Figure 3 ).

Table 1 - Blood donor samples reactive in the FMLELISA assay.

\begin{tabular}{ccr}
\hline Donor number & $\begin{array}{c}\text { FML-ELISA } \\
\text { reactivy at 492nm }\end{array}$ & Date \\
\hline 462. & .506 & 30.8 .94 \\
463. & .291 & 31.8 .94 \\
464. & .231 & 1.9 .94 \\
465. & .271 & 1.9 .94 \\
466. & .250 & 1.9 .94 \\
467. & .232 & 1.1 .94 \\
468. & .220 & 1.9 .94 \\
469. & .232 & 5.9 .94 \\
\hline
\end{tabular}

All the samples were tested at $1 / 100$ sera dilution. Results represent the absorbency values at $490 \mathrm{~nm}$. Normal sera gave values below 0.204 .
The 55kDa component of FML was recognized by normal sera from kala-azar endemic and nonendemic area, and sera from patients with tegumentar leishmaniasis, kala-azar or Chagas disease. This antigen is thus non-specific. Conversely the GP36 glycoprotein band was only detected in Western Blots by kala-azar patients' sera. No labeling was detected with sera of patients with tegumentar leishmaniasis, Chagas disease, or normal sera. The GP36 antigen of FML shows to be a marker of human kala-azar.

Finally the analysis of the protective potential of FML in experimental vaccination against visceral leishmaniasis was performed in the outbred swiss albino model. We have tested the potential activity

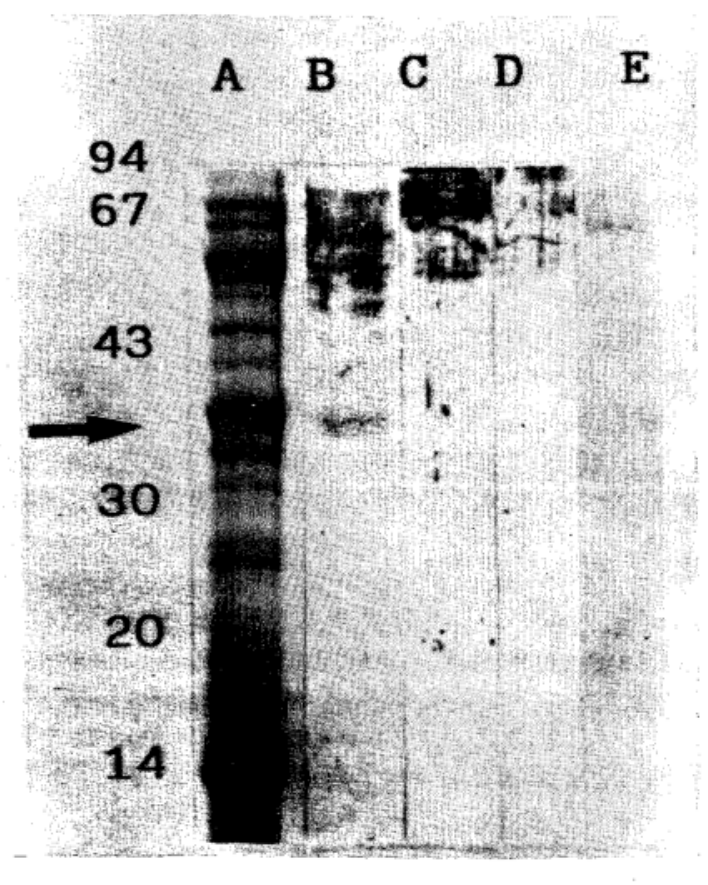

Figure 3 - SDS-PAGE and Western Blot analysis of FML antigen of L. donovani using human sera. Molecular

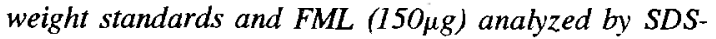
PAGE and stained with Coomassie Brilliant Blue R250, are indicated on the left side. Blotts containig 1-3ug FML were treated with: a: serum of a patient with confirmed kala-azar (11/11), b: serum of a normal donor from endemic area, $c$ : serum of a patient with tegumentar leishmaniasis (5/5), d: serum of a patient with Chagas disease (5/5). e: serum of normal heathy donor from nonendemic area (2/8). The arrow indicates the GP36 band. The number in brackets represent the samples assayed that showed the same profile of reactivity. 
of FML in protection of outbred swiss albino mice against the infection with $L$. donovani. We compared the administration of FML with Saponin through the intraperitoneal or subcutaneous route. Results of anti-FML antibodies are summarized in Figure 4A. Before the infection a pronounced speciffic response to $\mathrm{FML}(\mathrm{p}<0.001)$ was detected in animals immunized with FML and saponin, higher by the intraperitoneal than the subcutaneous route. After the infection, both group of mice showed an increased response whereas no response was detected in any control group. Taken together, these results show the slow establishment of immune response in mice, even when infected by this relatively high dose of $L$. donovani amastigotes. Indeed, no immunoglobulin secretion to FML was detected in untreated infected animals, at 15 days of infection. Noteworthy, the specific pre-stimulation with FML and saponin triggered the anti-FML antibody synthesis. The protective effect of this response is shown by the diminished parasite burden in host's tissues. Indeed, the parasite counts in liver were significantly decreased $(\mathrm{p}<0.001)$, in the same order of magnitude as the immunoglobulins to FML expanded Figure 4B. At this stage of experimental murine infection, parasites are found only in liver, and they infect the spleen only 30 days later (data not shown). No significant differences were detected between the saline and the saponin treated animais, in any parameter $(p>0.3)$. Taken
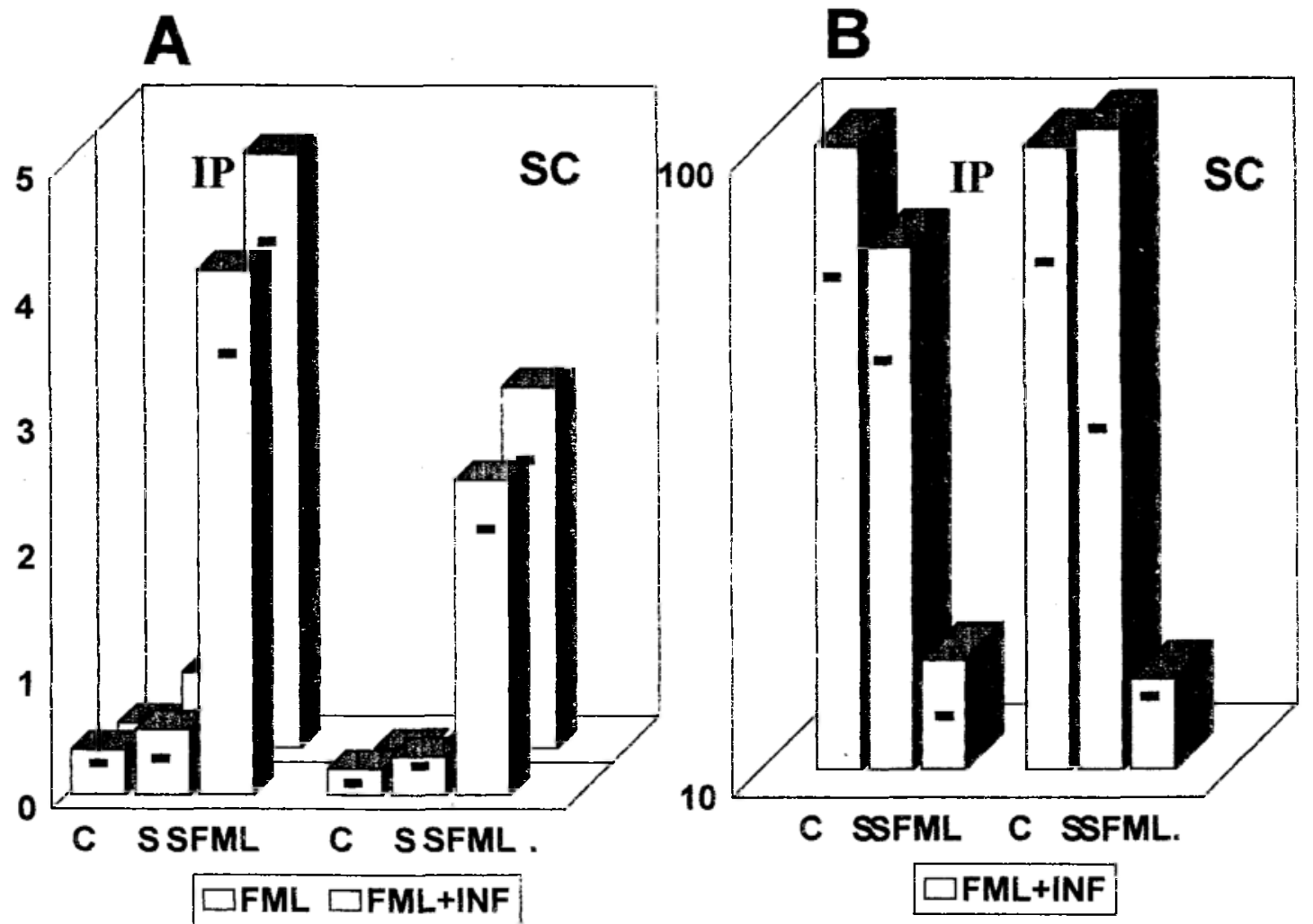

Figure 4 - Effect of FML on Leishmania donovani infection in swiss albino mice. In A: antibody response:open columns: seven days after three intraperitoneal (IP) or subcutaneous (SC) injections of control saline solution (C), $100 \mu \mathrm{g}$

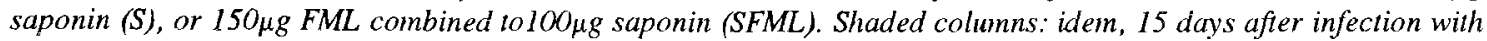
L. donovani. Results represent score mean values of the pool of sera of two independent experiments done in triplicates, using 4-5 mice in each group. In B: liver parasitic burden., of the same groups in A, after 15 days infection with $\mathrm{L}$. donovani. Results are expressed as percents of the average of LDU values (counts in 1000 cells) of liver imprints of infected mice, of two independent experiments, using 4 to 5 mice in each group. Horizontal bars represent standard errors. FML saponin treated mice, after infection, gave significantly different results $(p<0.001)$ when compared to all other groups. 
toguether these results represent an average of 80.0 $\%$ increase in speciffic antibody response and a $85.5 \%$ protection in reduction of parasite liver burden. Although the humoral response was higher in the case of intraperitoneal administration, no signifficant difference between the vias was shown in what concern to protective effect.

\section{DISCUSSION}

ELISA tests using crude native antigens are usually done in dilutions of 2 to $5 \mu \mathrm{g} / \mathrm{well}^{1516}$. In an improved ELISA assay, the recombinant GP63 antigen of $L$. chagasi was used in concentration of $1 \mu \mathrm{g} /$ well ${ }^{35} 39$. The FML is thus a very sensitive antigen, and standard ELISA tests can be done in dilutions increased by an order of magnitude. This sensitivity can be probably advantageously used in development of rapid and automated tests for kalaazar. This property of FMLcan be possibly attributed to its glycoproteic nature. Previous studies have attributed the species-specific characteristics of Leishmania glycoconjugates to their glycidic moiety ${ }^{28}$.

The presented results indicate that assays using FML can be highly sensitive and specific in diagnosis of kala-azar. This antigen can clearly separate visceral leishmaniasis from all the other closely related tegumentar infections caused by parasite of the genus Leishmania, with the sensitivity comparable to those reported for recombinant antigens ${ }^{35} 39$. Moreover, this antigen can identify inhabitants of endemic areas with a potential subclinical infection, and point out those with a high risk of evolution towards the overt severe disease. It can be also used to follow-up of the parasitologic cure. Different form previously reported data ${ }^{2}$, the FML antigen isolated from an African strain of $L$. donovani was accurate in diagnosis of South American visceral leishmaniasis, representing apparently a tool that can be used throughout the diagnostics of diseases caused by the $L$. donovani complex.

Two cases of a positive reaction of FML with sera of a patient without overt kala-azar were observed. The first was a patient with chronic disseminated muco-cutaneous leishmaniasis. This serum had high titers of IgG and IgM antibodies against $L$. braziliensis, but the parasite could not be isolated nor characterized. The second was from a patient with Chagas's disease. In both examples the possibility of a concomitant infection with $L$. donovani could not be ruled out since visceral leishmaniasis was also endemic in these regions. These two positive reactions are at present, of difficult interpretation. Their presence has decreased the specificity of the assay to $96 \%$. The FML antigen developed equal levels of sensitivity and specificity than the recombinant antigen used by Burns et al (1993) ${ }^{8}$. However, different from the recombinant antigen, FML is a a glycoproteic complex and its long lasting stability makes of it a good candidate for work in field assays. We were able to use the same batch for period over two years with no signifficant changes in its performance. The FML-ELISA test is now being used as a new tool for diagnosis, prognosis, cure survey of visceral leishmaniasis and it is used as an alternative to bone marrow punction in several human cases with no false negative or positive results. The test is performed routinely in the cited Hospital and Blood bank services. Furthermore a clinical and epidemical survey of perypherical areas of Natal, using the FML-ELISA test is underway.

In this study we described the presence of $L$. donovani sororeactive individuals among spontaneous blood donors in the kala-azar endemic area. This prevalence attained up to $17 \%$ of diary donors. These values are higher than those usually detected for chagasic donors in Rio de Janeiro. Recent results from our laboratory demostrated that blood transfusion is an efficient via of transmission of experimental kala-azar. No one of the 8 FMLELISA positive sera was reactive in the tests for Chagas' disease or other diseases, performed in the blood bank and therefore the use of these blood package units would be considered possible, since the presence of antibodies against Leishmania donovani would not be detected by the present used control tools. Since these specific antibody titers could be a signal of active infection and of a potential source of blood borne visceral leishmaniasis, the extension of the FML-ELISA screening in blood banks and the detailed study of each sororeactive case is extremely necessary.

We further analyzed by Western Blot the reactivity of human sera with FML. Isolated GP36 was only detected in Western Blots by kala-azar 
Sousa CBP, Gomes EM, Souza EP, Santos WR, Macedo SR, Medeiros LV, Luz K. The FML (Fucose Mannose Ligand) of Leishmania donovani. A new tool indiagnosis, prognosis, transfusional control and vaccination against human kala-azar. Revista da Sociedade Brasileira de Medicina Tropical 29:153-163, 1996.

patients' sera. No labeling was detected with sera of patients with tegumentar leishmaniasis, Chagas disease, or normal sera. The GP36 has shown to be the most specific fraction of the FML antigen. The GP36 component of FML could correspond in living parasites to a lower molecular weight component since its extraction procedure, favours the glycidic enrichment that could retard ist migration in SDS PAGE. The specificity of a 32-35 kDa band for kala-azar was suggested by Reed et al. $(1987)^{34}$, who used a total soluble extract of $L$ chagasi with sera of patients from Brazil. Circulating antigens of 30-35 kDa were detected in sera of human patients by monoclonal specific antibodies ${ }^{42}$ and were recovered from kidneys of $L$. donovani infected hamsters ${ }^{36}$. The GP36 may be thus shed in vivo by parasites, representing a circulating antigen. The isolation of GP36 antigen of FML is in progress.

Finally, the reported results indicate that FML may be a potential candidate for vaccination in visceral leishmaniasis. Both intraperitoneal or subcutaneous immunizations were effective. These results are particularly signifficant in view of the outbred nature of the experimental model. Indeed a high intragroup variation was expected. This protective effect of FML and saponin is in agree to previous evidences of the protective potential against experimental visceral leishmaniasis in CB hamsters and $\mathrm{Balb} / \mathrm{C}$ mice ${ }^{3031}$. In our conditions, saponin showed nor toxic neither unspeciffic effects. Its use as adjuvant was compared to Corynebacterium parvum, Freund Adjuvant, Alhydrogel, Bordetella pertussis and Muramyl dipeptide and considered to be advantageous ${ }^{4}$. In agreement with our results, saponin has been previously shown to be a good potentiator of anti-protozoan immunity in experimental vaccines against $T$ cruzi $^{37}$. However, saponins are discriminated as adjuvant because of their hemolytic properties ${ }^{3}$. For this reason, we started the comparative analysis of the hemolytic and ajuvant potential of different kind of saponins. Using the purified antigen DP72 for immunization of balb/c mice against $L$. donovani infection, a protective effect of the same order of magnitude was reported ${ }^{1633}$. However, in those works, for protection or lymphocyte proliferation assays, respectively, after sensitization with the antigen, the animals received different doses of promastigotes. It is consequently not clear if the described effects were due only to DP72 administration or to promastigote injection or to both of them. Two other antigens of Leishmania, extensively studied were candidates for vaccination against cutaneous Ieishmaniasis in mice, however, it was recently shown that GP63 is unable to induce lymphocyte proliferation in human leishmaniasis ${ }^{23}$ and that the ability of LPG to induce a protective response in mice is due to contaminant proteins or glycoproteins, called LPG associated proteins (LPGAP) ${ }^{17}$. Furthermore subcutaneous LPG vaccination against murine tegumentar leishmaniasis by the subcutaneous route showed to induce an increase of lesion size, instead of protection ${ }^{13}$. Recently, the immunization with one of the LPGAP flagellar proteins, present in a wide range of Leishmania species and in African trypanosomes, in the recombinant form, stimulates primed lymphocytes to proliferate in vitro ${ }^{40}$. The use of FML of Leishmania donovani and of its components in sorologycal screening for visceral leishmaniasis shows high sensitivity, specificity, stability and comparatively easier performance. Its use in Blood banks would improve the quality control to prevent blood borne infections. Furthermore it showed a signifficant potential on experimental vaccination against kala-azar. The study of the molecular aspects related to the described FML potentials is under progress.

\section{RESUMO}

O FML (Ligante de Fucose-Manose) de Leishmania donovani é una fração glicoproteica complexa. O seu potencialno diagnóstico da leishmaniose visceral humana foi testado com soros provenientes de Natal, Rio Grande do Norte, Brasil. O teste de FML-ELISA mostron 100\% de sensibilidade e $96 \%$ de especificidade, identificando pacientes com calazar declarado $(p<0.001$, comparados com soros normais) e individuos com infeç̧ão subclínica. Mais de $20 \%$ dos sororreativos assimptomáticos desenvolveram a doença no prazo de 10 meses. Na análise de doadores de sangue, $5 \%$ de sororeativos, atingindo até $17 \%$ num único dia foram detectados. A glicoproteina GP36do FHLé reconhecida especificamente por soros de pacientes com calazar. O potencial imunoprotetor do FML no calazar experimental foi testado no modelo swiss albino em combinação com saponina pelas vias subcutâneas elou intraperitoneal seguido de desafio com $2 \times 10^{7}$ amastigotas de Leishmania donovani. Um aumento de $80.0 \%$ na resposta de anticorpos especificos $(p<0.001)$ e a redução de $85.5 \%$ 
Sousa CBP, Gomes EM, Souza EP, Santos WR, Macedo SR, Medeiros LV, Luz K. The FML (Fucose Mannose Ligand) of Leishmania donovani. A new tool in diagnosis, prognosis, transfusional control and vaccination against human kala-azar. Revista da Sociedade Brasileira de Medicina Tropical 29:153-163, 1996.

da carga parasitária no figado $(p<0.001)$ foi detectado nos animais vacinados com FML e saponina, independentemente da via de administração.

Palavras-chaves: Glicoconjugado. Leishmania donovani. Calazar. Transfusão de sangue. Diagnostico.

\section{ACKNOWLEDGMENTS}

This research has been supported by FNS, FINEP, CNPQ, RHAE-CNPQ and CEPG-UFRJ. Dr. Telma C. Barros Freire from HEMONORTE, is acknowledgeded for sample collection facilities.

\section{REFERENCES}

1. Ashford DA, Badaró R, Eulalio C, Freire M. Miranda C, Zalis M, David, JR. Studies on the control of visceral leishmaniasis:validation of the Falcon assay screening test-enzyme linked immunosorbent assay (Fast-Elisa ${ }^{\text {TM}}$ ) for field diagnosis of canine visceral leishmaniasis. The American Journal of Tropical Medicine and Hygiene 48:1-8, 1993.

2. Badaró R, Reed SG, Barral A, Orge G, Jones TC. Evaluation of the microenzyme linked immunosorbent assay for antibodies in american visceral leishmaniasis:antigen selection for detection of infectionspecific responses. The American Journal of Tropical Medicine and Hygiene 35:72-78, 1986.

3. Bomford R. Saponin and other haemolysins (Vitamin A, aliphatic amines, polyene antibiotics) as adjuvants for SRBC in the mouse. International Archives of Allergy and Applied Immunology 63:170-177, 1980.

4. Bomford $R$. The comparative selectivity of adjuvants for humoral and cell mediated immunity II. Effect on delayed type hypersensitivity in the mouse, guinea pig, and cell mediated immunity to tumor antigens in the mouse of Freund's incomplete and complete adjuvant, alhydrogel, Corynebacterium parvum, Bordetella pertussis, muramyl dipeptide and saponin. Clinical and Experimental Immunology 39:435-441, 1984.

5. Borowy NK, Schell D, Schaeffer C, Overath P. Diagnostic of human african trypanosomiasis and visceral leishmaniasis based on detection of antiparasite-enzyme antibodies. Journal of Infectious Diseases 164:422-425, 1991.

6. Bradley DJ, Kirkley J. Regulation of Leishmania population within the host. I. Variable course of Leishmania donovani infection in mice. Clinical and Experimental Immunology 30, 119-129, 1977.

7. Brumpt E. Le Kala-azar. In: Masson e Cie (ed) Précis de Parasitologie, $6^{\text {eme }}$ edition, Collection de Précis Médicaux, Paris p. 256-277, 1949.

8. Burns Jr JM, Shreffler WG, Benson DR, Ghalib HW, Badaró R, Reed SG. Molecular characterization of a kinesin-related antigen of Leishmania chagasi that detects specific antibody in African and American Visceral Leishmaniasis. Proceedings of the National Academy of
Science USA 90:775-779, 1993.

9. Castellani A Chalmers AJ. Visceral Leishmaniasis In: Baillière, Tindall, Cox (eds) Manual of Tropical Medicine, $3^{\text {rd }}$ edition, University series, London p.1289-1307, 1919.

10. Cohen C, Corazza F, De Mol P, Brasseur D. Leishmaniasis acquired in Belgium. Lancet 338:128, 1991.

11. Convit J, Castellano PL, Rondon A, Penardi ME, Ulrich M, Castes M, Bloom B, Garcia L. Immunotherapy versus chemoterapy in localized Cutaneous Leishmaniasis. The Lancet I:401-404, 1987.

12. Grogl M, Daugirda JL, Hoover DL, Magill AJ, Berman J.Survaivability and infectivity of visce rotropic Leishmania tropica from Operation Desert Storm participates in human blood products maintainance under blood banking conditions. The American Journal of Tropical Medicine and Hygiene 49:308-315, 1993.

13. Handman E, Mitchell GF. The glycoconjugate derived from a Leishmania major receptor for macrophages is a suppressogenic disease promoting antigen in murine Cutaneous Leishmaniasis. Parasite Immunology 8:255263, 1986.

14. Holbrook TW, Cook JA, Parker BW. Immunization against Leishmania donovani: glucan as an adjuvant with killed promastigotes. The American Journal of Tropical Medicine and Hygiene 30:762-768, 1981.

15. Jaffe CL Zalis $M$. Use of purified parasite proteins from Leishmaniadonovani for the rapid serodiagnosis of visceral leishmaniasis. Journal of Infectious Diseases 157, 1212$1220,1988$.

16. Jaffe CL, Rachamim N, Sarfstein R. Characterization of two proteins from Leishmania donovani and their use for vaccination against visceral leishmaniasis. Journal of Immunology 144:699-706, 1990.

17. Jardim A, Tolson DL, Turco SJ, Pearson TW, Olafson RW.Leishmania donovani lipophosphoglycan T lymphocyte reactive component is a tightly associated protein complex. Journal of Immunology 147:3538-3544, 1991.

18. Jarecki-Black JC, James ER, Kirshtein JW, Kirshtein JD, Glassman AB. Leishmania donovani: immunization against infection as a function of parasite growth phase. The American Journal of Tropical Medicine and Hygiene 35:1117-1121, 1986

19. Kudo RR. Family 5 Trypanosomatidae Doflein. In:Thomas CC (ed) Protozoology, $4^{\text {th }}$ edition, Thomas Books, USA p. 355-356, 1960.

20. Marzochi, MCA, Marzochi KBF, Carvalho RW. Visceral Leishmaniasis in Rio de Janeiro. Parasitology Today 10:37-40, 1994

21. Mayrink W, William P, Costa CA, Magalhães PA, Melo HN, Dias M, Lima AO, Michalick MSM, Carvalho EF, Barros GC, Sessa PA, Alencar JE. An experimental vaccine against American dermal Leishmaniasis experience in the State of Espirito Santo Brazil. Annals of Tropical Medicine and Parasitology 79:259-269, 1985.

22. Mebrahtu YB, Hendricks LD, Oster CN, Lawyer PG, Perkins PV, Pamba H, Koech D, Roberts CR. Leishmania donovani parasites in the nasal secretions, tonsillopharyngeal mucosa, and urine centrifugates of visceral leishmaniasis patients in Kenya. American Journal 
Sousa CBP, Gomes EM, Souza EP, Santos WR, Macedo SR, Medeiros LV, Luz K. The FML (Fucose Mannose Ligand) of Leishmania donovani. A new tool in diagnosis, prognosis, transfusional control and vaccination against human kala-azar. Revista da Sociedade Brasileira de Medicina Tropical 29:153-163, 1996.

of Tropical Medicine and Hygiene 48:530-535, 1993.

23. Mendonça SCF, Russell DG, Coutinho SG. Analysis of the human $T$ cell responsiveness to purified antigens of Leishmania: Lypophosphoglycan (LPG) and glycoprotein 63 (GP63). Clinical and Experimental Immunology 83:472478, 1991 .

24. Modabber F. Experiences with vaccines against cutaneous leishmaniasis of men and mice. Parasitology 98 (S):49-60, 1989.

25. Modabber, F. Leishmaniasis. In: World Health Organization (ed) Tropical Disease Research. Progress. 1991-1992, Geneva p.77-87, 1993.

26. O'Daly CJA, Cabrera Z. Immunization of hamsters with TLCK-killed parasites induced protection against Leishmania infection. Acta Tropica 43:225-232, 1986.

27. Palatnik CB, Borojevic R, Previato JO, Mendonça-Previato L. Inhibition of Leishmania donovani promastigote internalization into murine macrophages by chemically defined parasite glycoconjugate ligands. Infection and Immunity 57:754-763, 1989.

28. Palatnik CB, Previato JO, Mendonça-Previato L, Borojevic R. A new approach to phylogeny of Leishmania: speciesspecificity of glycoconjugate ligands for promastigote internalization into murine macrophages. Parasitology Research 76:289-293, 1990.

29. Palatnik-de-Sousa CB, Dutra HS, Borojevic R. Leishmania donovani surface glycoconjugate GP36 is the major immunogen component of the Fucose-Mannose Ligand (FML). Acta Tropica 53:59-72, 1993.

30. Palatnik-de-Sousa CB, Paraguai de Souza E, Gomes EM, Borojevic R. Experimental murine Leishmania donovani infection: immunoprotection by the Fucose Mannose Ligand (FML). Brazilian Journal of Medical an Biologycal Research 27:547-551, 1994.

31. Palalnik-de-Sousa CB, Bunn Moreno MM, Paraguai de Souza E, Borojevic R. The FML vaccine (Fucose Mannose Ligand) protects hamsters from experimental kala-azar. Jounal of the Brazilian Society for the Advancement of Science. Ciência e Cultura. 46:290-296, 1994.

32. Palatnik de Sousa CB, Gomes EM, Paraguai de Souza E, Palatnik M, Luz KG, Borojevic R. The Fucose Mannose Ligand of Leishmania donovani in diagnosis and prognosis of visceral leishmaniasis (kala-azar). Transactions of the Royal Society of Tropical Medicine and Hygiene 89:(In press), 1995.
33. Rachamim N, Jaffe CL. Pure protein from Leishmania donovani protects mice against both Cutaneous and Viceral Leishmaniasis. Journal of Immunology 150:2322-2331, 1993.

34. Reed SG, Badaró R, Cherry Lloyd RM Identification of specific cross reactive antigen of Leishmania donovani chagasi by human infection sera. Journal of Immunology 138:1596-1601, 1987.

35. Reed SG, Schreffler WG, Burns JMJ, Scott JM, Orge MG, Ghalib MS, Badaró R. An improved serodiagnostic procedure for visceral leishmaniasis. The American Journal of Tropical Medicine and Hygiene 43:632-639, 1990.

36. Sartori A, Viana de Oliveira A, Roque Barreira MC, Rossi MA, Campos-Neto A. Immune complex glomerulonephritis in exprimental kala-azar. Parasite Immunology 9:93-103, 1987.

37. Scott MT, Bahr G, Modabber F, Afchain D, Chedid L. Adjuvant requirement for protective immunization of mice using Trypanosoma cruzi $90 \mathrm{~K}$ cell surface glycoprotein. International Archives of Allergy and Applied Immunology 74:373-377, 1984.

38. Scott JE, Schreffler WG, Ghalib HW, El Asad A, Siddig M, Badaró R, Reed SG. A rapid and simple diagnostic test for active visceral leishmaniasis. The American Journal of Tropical Medicine and Hygiene 44:272-277, 1991.

39. Schreffler WG, Burns JMJ, Badaró R, Ghalib HW, Button LL, McMaster R, Reed SG. Antibody responses of visceral leishmniasis patients to GP63, a major surface glycoprotein of Leishmania species. Journal of Infectious Diseases 167:426-430, 1993.

40. Tolson DL, Jardim AJ, Schnur L F, Stebeck C, Tuckey C, Beecroft RP, Teh HS, Olafson RW. Pearson TW. The kinetoplastid membrane protein 11 of Leishmani donovani and African trypanosomes is a potent stimulator of $\mathrm{T}$ lymphocyte proliferation. Infection and Immunity 62:48934899, 1994.

41. World Health Organization. Kala-azar surges on two front. TDR News 37:1-2, 1991.

42. Xiao-Su H, Qing L, Fang-King L, Tao-Lin Y, Ya-Jin W, Zhi Q, Ping Q, Ling L.Kala-azar infected serum circulating antigens and their characteristics detected by monoclonal antibodies. Chinese Medical Journal 101:1-6, 1988.

43. Youden J. Index for rating diagnostic tests. Cancer, 3:3235,1950 . 